\title{
Importance and outcome relevance of central pathology review in prostatectomy specimens: data from the SAKK 09/10 randomized trial on prostate cancer
}

Ghadjar, Pirus ; Hayoz, Stefanie ; Genitsch, Vera ; Zwahlen, Daniel R ; Hölscher, Tobias ; Gut, Philipp ; Guckenberger, Matthias ; Hildebrandt, Guido ; Müller, Arndt-Christian ; Putora, Paul Martin ;

Papachristofilou, Alexandros ; Stalder, Lukas ; Biaggi-Rudolf, Christine ; Sumila, Marcin ; Kranzbühler, Helmut ; Najafi, Yousef ; Ost, Piet ; Azinwi, Ngwa C ; Reuter, Christiane ; Bodis, Stephan ; Khanfir, Kaouthar ; Budach, Volker ; Aebersold, Daniel M ; Thalmann, George N ; Swiss Group for Clinical

Cancer Research (SAKK)

\begin{abstract}
OBJECTIVES: To conduct a central pathology review within a randomized clinical trial on salvage radiation therapy (RT) in the presence of biochemical recurrence after prostatectomy to assess whether this results in shifts of histopathological prognostic factors such as the Gleason Score. PATIENTS AND METHODS: A total of 350 patients were randomized and specimens of $279(80 \%)$ of the patients were centrally reviewed by a dedicated genitourinary pathologist. The Gleason Score, tumor classification and resection margin status were reassessed and compared with the local pathology reports. Agreement was assessed using contingency tables and Cohen's Kappa. Additionally, the association between other histopathological features (e.g. largest diameter of carcinoma) with rapid biochemical progression (up to 6 months after salvage RT) was investigated. RESULTS: There was good concordance between central pathology review and local pathologists for seminal vesicle invasion [pT3b: $91 \%$; $\mathrm{k}=0.95$ $(95 \%$ CI $0.89,1.00)]$, for extraprostatic extension [pT3a/b: 94\%; $\mathrm{k}=0.82(95 \%$ CI $0.75,0.89)]$, and for positive surgical margin status $[87 \%$; $\mathrm{k}=0.7$ (95\% CI 0.62, 0.79)]. Agreement was lower for Gleason score $[78 \% ; \mathrm{k}=0.61$ (95\% CI 0.52, 0.70)]. The median largest diameter of carcinoma was $16 \mathrm{~mm}$ (range, 3-38 mm). A total of 49 patients $(18 \%)$ experienced rapid biochemical progression after salvage RT. Largest diameter of carcinoma [odds ratio (OR): 2.04 (95\% Confidence interval (CI): 1.30, 3.20); p = 0.002], resection margin status [OR: $0.36(95 \% \mathrm{CI}: 0.18,0.72) ; \mathrm{p}=0.004]$ and Gleason score [OR: 1.55 (95\% CI: 1.00, 2.42); $\mathrm{p}=0.05]$ remained associated with rapid progression after salvage RT after backward selection. CONCLUSION: The results of the central pathology analyses reveal concordant results for seminal vesicle invasion, extraprostatic extension, positive surgical margin but lower agreement for Gleason Score. Largest diameter of carcinoma was found to be a potential prognostic factor for rapid biochemical progression after salvage RT. This article is protected by copyright. All rights reserved.
\end{abstract}

DOI: https://doi.org/10.1111/bju.13742

Posted at the Zurich Open Repository and Archive, University of Zurich ZORA URL: https://doi.org/10.5167/uzh-130509

Journal Article

Accepted Version

Originally published at: 
Ghadjar, Pirus; Hayoz, Stefanie; Genitsch, Vera; Zwahlen, Daniel R; Hölscher, Tobias; Gut, Philipp; Guckenberger, Matthias; Hildebrandt, Guido; Müller, Arndt-Christian; Putora, Paul Martin; Papachristofilou, Alexandros; Stalder, Lukas; Biaggi-Rudolf, Christine; Sumila, Marcin; Kranzbühler, Helmut; Najafi, Yousef; Ost, Piet; Azinwi, Ngwa C; Reuter, Christiane; Bodis, Stephan; Khanfir, Kaouthar; Budach, Volker; Aebersold, Daniel M; Thalmann, George N; Swiss Group for Clinical Cancer Research (SAKK) (2017). Importance and outcome relevance of central pathology review in prostatectomy specimens: data from the SAKK 09/10 randomized trial on prostate cancer. BJU International, 120(5B):E45-E51. DOI: https://doi.org/10.1111/bju.13742 
Received Date : 02-Sep-2016

Revised Date : 27-Nov-2016

Accepted Date : 12-Dec-2016

Article type : Original Article

Article Categort : Urological Oncology

\section{Importance and outcome relevance of central pathology review in prostatectomy} specimens: data from the SAKK 09/10 randomized trial on prostate cancer.

Pirus Ghadjar $\mathrm{MD}^{1^{*}}$, Stefanie Hayoz $\mathrm{PhD}^{2}$, Vera Genitsch $\mathrm{MD}^{3}$, Daniel R. Zwahlen $\mathrm{MD}^{4}$, Tobias Hölscher $\mathrm{MD}^{5}$, Philipp Gut MD ${ }^{6}$, Matthias Guckenberger $\mathrm{MD}^{7}$, Guido Hildebrandt $\mathrm{MD}^{8}$, Arndt-Christian Müller $\mathrm{MD}^{9}$, Martin P. Putora MD ${ }^{10}$, Alexandros Papachristofilou MD ${ }^{11}$, Lukas Stalder $\mathrm{PhD}^{12}$, Christine Biaggi-Rudolf $\mathrm{MSc}^{2}$, Marcin Sumila $\mathrm{MD}^{13}$, Helmut Kranzbühler $\mathrm{MD}^{14}$, Yousef Najafi MD ${ }^{15}$, Piet Ost ${ }^{16}$, Ngwa C. Azinwi MD ${ }^{17}$, Christiane Reuter MD ${ }^{18}$, Stephan Bodis $\mathrm{MD}^{19}$, Kaouthar Khanfir MD ${ }^{20}$, Volker Budach $\mathrm{MD}^{21}$, Daniel M. Aebersold MD ${ }^{22}$, George N. Thalmann $M^{23}$ for the Swiss Group for Clinical Cancer Research (SAKK)

Department of Radiation Oncology, Inselspital, Bern University Hospital, and University of Bern, Switzerland, now at Charité Universitätsmedizin Berlin, Germany ${ }^{1}$, SAKK Coordinating Center, Bern, Switzerland ${ }^{2}$, Department of Pathology of the University of Bern, Switzerland ${ }^{3}$, Departments of Radiation Oncology, Kantonsspital Graubünden, Chur, Switzerland ${ }^{4}$, University Hospital Dresden, Germany ${ }^{5}$, Kantonsspital Luzern, Switzerland, now at Hirslanden Hospital Group, Zürich, Switzerland ${ }^{6}$, University Hospital Würzburg, Germany, now at University Hospital Zürich, Switzerland ${ }^{7}$, University Hospital Rostock, Germany ${ }^{8}$, University Hospital Tübingen, Germany ${ }^{9}$, Kantonsspital St. Gallen, Switzerland ${ }^{10}$, University Hospital Basel, Switzerland ${ }^{11}$, SAKK Coordinating Center, Bern, Switzerland, now at University of Bern, Switzerland $^{12}$, Hirslanden Hospital Group, Zürich, Switzerland ${ }^{13}$, Stadtspital Triemli, Zürich, Switzerland ${ }^{14}$, University Hospital Zürich, Switzerland ${ }^{15}$, Ghent University Hospital, Belgium ${ }^{16}$, Istituto Oncologico della Svizzera Italiana, Bellinzona, Switzerland ${ }^{17}$, Kantonsspital Münsterlingen, Switzerland ${ }^{18}$, Kantonsspital Aarau, Switzerland $^{19}$, Hôpital Valais, Sion, Switzerland ${ }^{20}$, Charité Universitätsmedizin Berlin, Germany $^{21}$, Inselspital, Bern University Hospital, Switzerland ${ }^{22}$, Department of Urology, Inselspital, Bern University Hospital, Switzerland ${ }^{23}$

This article has been accepted for publication and undergone full peer review but has not been through the copyediting, typesetting, pagination and proofreading process, which may lead to differences between this version and the Version of Record. Please cite this article as doi:

10.1111/bju. 13742

This article is protected by copyright. All rights reserved. 


\section{ACKNOWLEGMENT}

The SAKK 09/10 trial is funded by grants provided by the Hedy and Werner Berger-Janser Foundation, Krebsforschung Schweiz (Swiss cancer research foundation), Radio-Onkologie Berner Oberland AG, Switzerland and Swiss State Secretariat for Education, Research and Innovation (SERI).

\section{${ }^{*}$ Correspondence}

Department of Radiation Oncology, Charité Universitätsmedizin Berlin, Augustenburger Platz 1, 13353 Berlin, Germany

Tel.: +49 30450 657055; Fax.: +49 30450 7527152; Email: pirus.ghadjar@ charite.de (Pirus Ghadjar, MD)

\section{Running title: Importance of central pathology review}

\section{ABSTRACT}

Objectives: To conduct a central pathology review within a randomized clinical trial on salvage radiation therapy (RT) in the presence of biochemical recurrence after prostatectomy to assess whether this results in shifts of histopathological prognostic factors such as the Gleason Score.

Patients and Methods: A total of 350 patients were randomized and specimens of $279(80 \%)$ of the patients were centrally reviewed by a dedicated genitourinary pathologist.

The Gleason Score, tumor classification and resection margin status were reassessed and compared with the local pathology reports. Agreement was assessed using contingency tables and Cohen's Kappa. Additionally, the association between other histopathological features (e.g. largest diameter of carcinoma) with rapid biochemical progression (up to 6 months after salvage RT) was investigated.

Results: There was good concordance between central pathology review and local pathologists for seminal vesicle invasion [pT3b: $91 \%$; $k=0.95(95 \% \mathrm{Cl} \mathrm{0.89,1.00)}$ ], for extraprostatic extension [pT3a/b: $94 \%$; $\mathrm{k}=0.82(95 \% \mathrm{Cl} 0.75,0.89)]$, and for positive surgical margin status [87\%; $\mathrm{k}=0.7(95 \% \mathrm{Cl} 0.62,0.79)$ ]. Agreement was lower for Gleason score $[78 \% ; \mathrm{k}=0.61(95 \% \mathrm{Cl} 0.52,0.70)]$. The median largest diameter of carcinoma was $16 \mathrm{~mm}$

This article is protected by copyright. All rights reserved. 
(range, 3-38 mm). A total of 49 patients (18\%) experienced rapid biochemical progression after salvage RT. Largest diameter of carcinoma [odds ratio (OR): 2.04 (95\% Confidence interval $(\mathrm{Cl}): 1.30,3.20) ; \mathrm{p}=0.002$ ], resection margin status [OR: $0.36(95 \% \mathrm{Cl}: 0.18,0.72)$; $p=0.004$ ] and Gleason score [OR: $1.55(95 \% \mathrm{Cl}: 1.00,2.42) ; \mathrm{p}=0.05]$ remained associated with rapid progression after salvage $\mathrm{RT}$ after backward selection.

Conclusion: The results of the central pathology analyses reveal concordant results for seminal vesicle invasion, extraprostatic extension, positive surgical margin but lower agreement for Gleason Score. Largest diameter of carcinoma was found to be a potential prognostic factor for rapid biochemical progression after salvage RT.

\section{INTRODUCTION}

Patients with biochemical recurrence after prostatectomy without evidence of distant metastatic disease commonly undergo early salvage radiation therapy (RT) of the prostate bed as their major curative treatment approach. There are several established pathological features such as the Gleason Score, tumor classification and resection margin status which can serve as prognostic factors for the outcome after salvage RT and thus must be assessed in a standardized fashion $(1,2)$. However, it has been previously described that these factors could significantly vary when being assessed by dedicated genitourinary pathologist in a central pathology review $(3,4,5)$. This may influence the outcome analyses of clinical trials and therefore the use of central pathology reviews is recommended (6).

Moreover, once centrally reviewed, additional histopathological features can uniformly be assessed which can potentially serve as additional prognostic factors.

It has been described that around one fifth of patients experience rapid biochemical progression after RT and these patients may harbor micrometastatic or radioresistant disease and may require a more tailored treatment approach (7). Thus it it appears to be important to search for clinical and histopathological predictors for rapid biochemical progression.

We describe here the differences between the central and local pathology results for patients treated within our clinical trial on salvage RT and analyze the association of several histopathological features and rapid biochemical progression after salvage RT.

This article is protected by copyright. All rights reserved. 


\section{PATIENTS AND METHODS}

Trial design and conduct

Between 02/2011 and 04/2014, 350 patients were enrolled in an international phase III randomized controlled trial (Swiss Group for Clinical Cancer Research, SAKK 09/10) on dose-intensified (70 Gy over 7 weeks) versus standard-dose (64 Gy over 6.4 weeks) salvage $\mathrm{RT}$ in biochemically relapsed prostate cancer patients without macroscopic disease as previously described (8). The trial was conducted in 28 hospitals (Switzerland: 14, Germany: 11, Belgium: 3). Patients were eligible if they had evidence of biochemical recurrence (two consecutive rises in prostate-specific antigen (PSA) with final PSA $>0.1 \mathrm{ng} / \mathrm{ml}$, or 3 consecutive rises) and a PSA at randomization of $\leq 2 \mathrm{ng} / \mathrm{ml}$. The trial was registered under ClinicalTrials.gov identifier NCT01272050. The full list of inclusion and exclusion criteria can be found at ClinicalTrials.gov web site.

Radical prostatectomy was performed at least 12 weeks before randomization and was not part of this trial. All prostatectomy techniques were permitted. Within 16 weeks prior to randomization, either a MRI (recommended) or a multislice CT of the abdomen and pelvis was mandatory to exclude macroscopic local recurrence or lymph node metastases.

The primary endpoint of the trial was freedom from biochemical progression. The trial was designed as a two-arm phase III trial, assuming a median freedom from biochemical progression $\leq 3.8$ years for the null hypothesis, and $\geq 5.8$ years for the alternative hypothesis (i.e. absolute difference $=2$ years, hazard ratio $=0.6526$ ). The one-sided type I error was $5 \%$ and the power $80 \%$. The number of events required for primary analysis was 139 , and the sample size 350 patients.

\section{Central pathology Review}

The pathological review was performed by a single pathologist with experience in urogenital pathology (VG) and included the examination of all slides of the radical prostatectomy specimen.

Central pathology review was defined as mandatory in the trial protocol. Before centers were opened for accrual a pathology agreement form had to be signed by the main local pathologists stating that its institution is willing to submit slides of the prostatectomy specimen to the central pathology review which was conducted at the department of pathology of the University of Bern, Switzerland. Local pathologists were required to send in hematoxylin-eosin ( $\mathrm{HE}$ ) stained slides pseudonymized together with a report of the local pathology assessment. Gleason Score, tumor classification, presence of extraprostatic 
extension, invasion of seminal vesicles, and surgery margin status were recorded. If extracapsular extension was present, its extent was assessed according to Wheeler criteria (focal: neoplastic glands outside the prostate $<1$ high power field, hpf on $\leq 2$ separat sections neoplastic glands outside the prostate, established: anything more extensive than focal) and sidedness were recorded (anterior, apical, base, posterolateral) (9). Extraprostatic extension was defined as involvement off fat and/or loos connective tissue in plane of fat or beyond, involvement of perienural space in large neurovascular bundles, bulging tumor beyond the normal contours of the prostate gland, sometimes with desmoplastic stromal reaction (9). Positive surgical margin (PSM) status was recorded in case of the presence of tumor cells within the inked margin. For PSM, apical and non-apical (designated as anterior, base, posterolateral or seminal vesicles) involvement was distinguished.

The following local pathology features were obtained by case report form assessment and thus available in the database: tumor classification, Gleason pattern and Score, PSM status.

Central pathology review was carried out according to defined standards (3) and the Gleason Score was assigned according to the 2005 International Society of Urological Pathology (ISUP) consensus (10). Additionally, a new grading system was used to re-classify patients and to compare changes between local and central pathology assessment (11). For tumor classification the 2009 American Joint Committee on Cancer Staging System was used.

Furthermore, the presence of lymphovascular and perineural invasion was assessed, as well as the localization of the largest lesion, the Gleason score within the largest lesion and the largest diameter of carcinoma. These variables were not available for the local pathology assessments and could thus not be compared.

A total of 279 (80\% of the 350 trial participants) of prostatectomy specimens provided by local pathologists of 23 centers were reviewed. The remaining samples could not be analyzed because they were not provided by the local pathologists despite multiple reminders.

\section{Statistical analysis}

All patients who completed at least one salvage RT session and whose prostatectomy specimens were reviewed by the central pathologist were included in this analysis.

The assessments from local and review pathology were compared using contingency tables and Cohen's Kappa.

PSA doubling time after prostatectomy was calculated from the natural log of 2 divided by the slope of the relationship between the time of PSA measurement and the log of PSA using

This article is protected by copyright. All rights reserved. 
linear regression for each patient using all PSA measurements from prostatectomy until randomization.

The PSA values during the first 6 months after completion of salvage RT were used to assess PSA change. Patients were discriminated between rising PSA at any time during the first 6 months after completion of salvage RT (defined as rapid biochemical progression) and PSA response or stable PSA during the first 6 months after completion of salvage RT. Histopathological features were compared between the two patient groups using Wilcoxon rank sum tests for continuous variables and Fisher's exact tests for categorical variables. Furthermore, univariable and multiple logistic regression models with backward selection were applied to investigate the influence of preselected histopathological features and clinical parameters on rapid biochemical progression. Before applying the models pairwise correlations between the variables were investigated descriptively to avoid multicollinearity.

Two-tailed tests with significance level 0.05 were used for all analyses. As no adjustment for multiple testing for these analyses was made, they were exploratory and hypothesis generating. All analyses were performed using SAS 9.4 (SAS Institute) and R 3.2.4 (http://www.r-project.org).

\section{RESULTS}

$227(81 \%)$ of patients experienced a PSA reduction $(n=225)$ or stable PSA values $(n=2)$ in their first two follow-up visits ( 3 and 6 months after completion of RT) as compared to the pre-salvage RT value. The remaining 49 patients (18\%) experienced rising PSA and were considered as having rapid biochemical progression. Three patients (1\%) had missing PSA values after RT.

The median PSA prior to salvage RT was $0.3 \mathrm{ng} / \mathrm{mL}$ (range, $0.0-1.4 \mathrm{ng} / \mathrm{mL}$ ) and the median PSA doubling time prior to salvage RT was 7.6 months (range -155.3 - 95.6) and the PSA velocity prior to salvage RT was $0.1 \mathrm{ng} / \mathrm{mL} /$ year (range $-0.0-2.6$ ).

Level of agreement between review and local pathology

There was good concordance between central review and local pathologists regarding seminal vesicle invasion [pT3b: $91 \% ; \mathrm{k}=0.95(95 \% \mathrm{Cl} 0.89,1.00)$ ], PSM status [87\%; $\mathrm{k}=$ $0.7(95 \% \mathrm{Cl} 0.62,0.79)$ ], and for extraprostatic extension [pT3a/b: $94 \% ; \mathrm{k}=0.82(95 \% \mathrm{Cl}$ $0.75,0.89)]$.

Among the 115 patients with extraprostatic extension according to local pathology 108 (94\%) were confirmed by central pathology. Of the 164 patients being considered pT2 according to local pathology $146(89 \%)$ were confirmed as pT2 but $18(11 \%)$ were identified to be pT3 according to central pathology review. Thus the proportion of patients with pT3 increased from 41 to $45 \%$ after the central pathology review (Table 1 ).

This article is protected by copyright. All rights reserved. 
Of the 152 patients with negative surgical margins according to local pathology, 124 (82\%) were confirmed as R0 and 26 (17\%) were considered as PSM after central pathology review. For three patients surgical margin status was not available from the central review. Of the 127 patients with PSM according to local pathology, 111 (87\%) were confirmed as PSM but $15(12 \%)$ were considered R0. As a result the rate of patients being considered as PSM increased to $49 \%$ (pathologic review: 137 of 279 specimens) compared with $45 \%$ (local pathologists: 127 of 279$)$.

Agreement was lower for Gleason score $(78 \%$; k=0.61 (95\% Cl $0.52,0.70)$ ), whereby the pathology review resulted in a shift of the score from lower as well as higher levels to Gleason 7 (Table 2). Interestingly, the agreement was higher for the primary Gleason pattern $(\mathrm{k}=0.61)$ than for the secondary Gleason pattern $\mathrm{k}=0.41)$ (Table 2). When comparing the new grading system, a similar agreement between local pathology and central review was found (65\%; k=0.65 (95\% Cl 0.58, 0.71)) (data not shown).

Assessment of additional histopathological features

A total of 244 patients (88\%) were found to be positive for perineural invasion and a total of 33 patients $(12 \%)$ were positive for lymphovascular invasion. The median largest diameter of carcinoma was $16 \mathrm{~mm}$ (range, $3-38 \mathrm{~mm}$ ). Continuous additional histopathological variables were summarized in Table 3.

Association between clinical and histopathological features and rapid biochemical progression

The results of the comparison of histopathological features between patients with rapid biochemical progression and patients with stable PSA or PSA response are shown in Table 4. After applying multivariable logistic regression models with backward selection, largest diameter of carcinoma [odds ratio (OR): 2.04 (95\% Confidence interval (CI): 1.30, 3.20); $\mathrm{p}=$ 0.002], resection margin status [OR: 0.36 (95\% Cl: 0.18, 0.72); $p=0.004$ ] and Gleason score [OR: 1.55 (95\% Cl: 1.00, 2.42); $p=0.05$ ] remained significantly associated with rapid biochemical progression after salvage RT. In a next step these three variables as well as clinical variables were included in multiple logistic regression models. Again largest diameter, resection margin status and Gleason score remained significantly associated with rapid biochemical progression after salvage RT after backward selection (Table 5).

This article is protected by copyright. All rights reserved. 


\section{DISCUSSION}

The results of the present central pathology review analysis confirmed a good concordance for major histopathological prognostic factors such as seminal vesicle invasion, extraprostatic extension, positive surgery margin but lower agreement for Gleason Score. Additionally, we could identify the diameter of largest carcinoma as a potential prognostic factor for rapid biochemical progression after salvage RT.

Van der Kwast described the results of a central pathology review of 552 radical prostatectomy specimens. They found a high concordance rate for seminal vesicle invasion $(94 \%, \mathrm{k}=0.83)$ but the agreement was much less for extraprostatic extension $(57.5 \%, \mathrm{~K}=0.33)$ and for surgical margin status $(69.4 \%, \mathrm{k}=0.45)(3)$.

Bottke et al. found similar results with a good concordance for seminal vesicle invasion (91\%; $\mathrm{k}=0.76)$, and the agreement for extraprostatic extension $(75 \% ; \mathrm{k}=0.74)$ and surgical margin status (84\%; $k=0.65)$ being lower. Again, concordance was much less for Gleason score $(47 \% ; k=0.42)(5)$.

In an analysis of 2015 radical prostatectomy specimen others have also described a good concordance for seminal vesicle invasion (97.6\%; $\mathrm{k}=0.82)$, and the agreement for extraprostatic extension (82.5\%; $\mathrm{k}=0.59$ ) and surgical margin status $(87.5 \% ; \mathrm{k}=0.73$ ) being lower and Gleason Score being less concordant with $54.8 \%$ (4).

The concordance rates of our study for seminal vesicle invasion, extraprostatic extension and for PSM status and Gleason score compared well with the results of the three other mentioned studies (3-5).

The difference between the local and central review regarding Gleason score is not surprising. The application of the Gleason grading system changed repeatedly over time and particularly the consensus report by the ISUP 2005 (10), which was used for central pathology review, resulted in a distinct shift of Gleason grades. Since the prostatectomy specimens included in the present study date from different years back to 1998, the differences in Gleason grading can be well explained by these changes in grading practice. Regarding resection margins and extraprostatic extension there is missing standardization and variability between different institutions. This issue was addressed and changed only in the ISUP working group reports on handling and staging of radical prostatectomy specimens (9).

However, the central pathology review relevantly shifted the assessment of important prognostic factors and should therefore routinely be conducted within multicenter clinical trials.

This article is protected by copyright. All rights reserved. 
Specifically, the higher total rate of patients being considered as pT3 (45\% instead of $41 \%$ ) and as having a PSM (49\% instead of $45 \%$ ) after central pathology review would have led to more patients undergoing adjuvant RT after radical prostatectomy. On the other hand the shifts recognized by the central pathology review may influence the patients prognosis after $\mathrm{RT}$ as provided by a contemporary validated nomogram and are thus of interest (12).

Beyond these standard histopathological features as mentioned above there weren't other histopathological features which were routinely assessed and thus in today's clinical practice no other pathological variables are being considered as major prognostic factors (2).

We took advantage of the possibility to uniformly assess several other histopathological features which could potentially serve as future prognostic factors. We then divided the patients in men with PSA response or stable PSA and men with rapid biochemical progression in the early phase of follow-up after salvage RT and identified the largest diameter of carcinoma to be independently associated with rising PSA after salvage RT. Patients with rapid biochemical progression likely harbor micrometastatic disease or radioresistant disease and may benefit from more tailored treatment e.g. addition of androgen deprivation therapy (ADT) (7). The prognostic significance of largest diameter of carcinoma has been described controversially, some have described it as independent prognostic factor (13) others as less important (14). Once our trial will have mature biochemical control results we will repeat the analysis to identify prognostic factors and might be able to include some of the histopathological features in a Nomogram (2). No relevant differences in largest diameter of carcinoma were observed between the two treatment arms. Others have described genomic classifier to be able to predict metastases among men receiving salvage $R T$ for biochemically recurrent prostate cancer (15). A combination of histopathological features as assessed by our central pathology review might also be able in helping to detect patients who may benefit from tailored salvage RT treatment in terms of RT dose and / or additional ADT.

This analysis has limitations. Even though central pathology review should have been done in all patients, due to logistical reasons it was only performed in $80 \%$ of patients. As patients underwent radical prostatectomy prior to trial enrollment, the prostatectomy specimen were processed according to the standards of the local sites. While the determination of rapid biochemical progression was based on the first regular follow-up visits, biochemical control data has not matured yet and more solid oncological endpoints such as metastasis-free survival are not yet available for analysis.

Conclusion: The results of the central pathology analyses revealed discordant results for seminal vesicle invasion, extraprostatic extension, positive surgical margin as well as

This article is protected by copyright. All rights reserved. 
Gleason score. Largest diameter of carcinoma was found to be a potential prognostic factor for rapid biochemical progression after salvage RT.

\section{ACKNOWLEGMENTS}

The SAKK 09/10 trial is funded by grants provided by the Hedy and Werner Berger-Janser Foundation, Krebsforschung Schweiz (Swiss cancer research foundation), Radio-Onkologie Berner Oberland AG, Switzerland and Swiss State Secretariat for Education, Research and Innovation (SERI). We thank Professor Aurel Perren for coordinating the central pathology review involving the Tissue Bank Bern (TBB).

\section{REFERENCES}

1. Montironi R, van der Kwast $T$, Boccon-Gibod $L$, et al. Handling and pathology reporting of radical prostatectomy specimens. Eur Urol 2003;44:626-36.

2. Fossati N, Karnes RJ, Cozzarini C, et al. Assessing the Optimal Timing for Early Salvage Radiation Therapy in Patients with Prostate-specific Antigen Rise After Radical Prostatectomy.Eur Urol. 2016 Apr;69(4):728-33.

3. van der Kwast TH, Collette L, Van Poppel H, et al. Impact of pathology review of stage and margin status of radical prostatectomy specimens (EORTC trial 22911). Virchows Arch 2006;449:428-34.

4. Kuroiwa K, Shiraishi T, Ogawa O, et al. Discrepancy between local and central pathological review of radical prostatectomy specimens. Clinicopathological Research Group for Localized Prostate Cancer Investigators. J Urol. 2010;183:952-7.

5. Bottke D, Golz R, Störkel S, et al. Phase 3 study of adjuvant radiotherapy versus wait and see in pT3 prostate cancer: impact of pathology review on analysis. Eur Urol. 2013;64:193-8.

6. Montironi R, Lopez-Beltran A, Cheng L, Montorsi F, Scarpelli M. Central prostate pathology review: should it be mandatory? Eur Urol. 2013;64:199-201; discussion 202-3.

7. Jackson WC, Desai NB, Tumati V, et al. Predictors of Rapid Treatment Failure After Postoperative Radiation Therapy: A Multicenter Study. Int J Radiat Oncol Biol Phys. 2016 Oct 1;96(2S):S184-S185.

8. Ghadjar P, Hayoz S, Bernhard J, et al. Acute Toxicity and Quality of Life After DoseIntensified Salvage Radiation Therapy for Biochemically Recurrent Prostate Cancer After Prostatectomy: First Results of the Randomized Trial SAKK 09/10. J Clin Oncol. 2015 Dec 10;33(35):4158-66.

This article is protected by copyright. All rights reserved. 
9. Magi-Galluzzi C, Evans AJ, Delahunt B et al. International Society of Urological Pathology (ISUP) Consensus Conference on Handling and Staging of Radical Prostatectomy Specimens. Working group 3: extraprostatic extension, lymphovascular invasion and locally advanced disease. Mod Pathol. 2011;24(1):26-38.

10. Epstein JI, Allsbrook WC, Amin MB, Egevad LL. The 2005 International Society of Urological Pathology (ISUP) consensus conference on gleason grading of prostatic carcinoma. Am J Surg Pathol 2005; 29: 1228-42.

11. Epstein JI, Zelefsky MJ, Sjoberg DD et al. A Contemporary Prostate Cancer Grading System: A Validated Alternative to the Gleason Score. Eur Urol. 2016;69:428-35.

12. Tendulkar RD, Agrawal S, Gao T, et al. Contemporary Update of a Multi-Institutional Predictive Nomogram for Salvage Radiotherapy After Radical Prostatectomy.

J Clin Oncol. 2016 Aug 15. [Epub ahead of print]

13. Eichelberger LE, Koch MO, Eble JN, et al. Maximum tumor diameter is an independent predictor of prostate-specific antigen recurrence in prostate cancer.

Mod Pathol. 2005;18:886-90.

14. Salomon L, Levrel O, Anastasiadis AG, et al. Prognostic significance of tumor volume after radical prostatectomy: a multivariate analysis of pathological prognostic factors.

Eur Urol. 2003;43:39-44.

15. Freedland SJ, Choeurng V, Howard L, et al. Utilization of a Genomic Classifier for Prediction of Metastasis Following Salvage Radiation Therapy after Radical Prostatectomy.

Eur Urol. 2016 [Epub ahead of print]

\section{CONFLICT OF INTERST DISCLOSURE}

There is no conflict of interest to disclose.

This article is protected by copyright. All rights reserved. 
Table 1: Distribution of tumor classification after local vs. central pathological assessment

\begin{tabular}{|c|c|c|c|c|c|c|c|c|}
\hline \multirow[b]{3}{*}{ Variable } & \multicolumn{5}{|c|}{$\begin{array}{l}\text { Pathological tumor classification } \\
\text { (local) }\end{array}$} & \multirow{3}{*}{$\begin{array}{c}\text { exact } \\
\text { concordance } \\
\\
\%\end{array}$} & \multirow{3}{*}{$\begin{array}{c}\text { under } \\
\text { staging } \\
\text { by LR vs } \\
\text { CR } \\
\%\end{array}$} & \multirow{3}{*}{$\begin{array}{c}\text { over } \\
\text { staging } \\
\text { by LR vs } \\
\text { CR } \\
\%\end{array}$} \\
\hline & \multirow{2}{*}{$\begin{array}{r}\text { pT2a } \\
\text { (N=1 } \\
n\end{array}$} & \multirow{2}{*}{$\begin{array}{r}\text { pT2 } \\
\text { (N=1 } \\
n\end{array}$} & \multirow{2}{*}{$\begin{array}{r}\text { pT2 } \\
\mathrm{N}=14 \\
\mathrm{n}\end{array}$} & \multirow{2}{*}{$\begin{array}{c}\mathrm{pT} 3 a \\
(\mathrm{~N}=81) \\
n\end{array}$} & \multirow{2}{*}{$\begin{array}{c}\text { pT3b } \\
(\mathrm{N}=34) \\
n\end{array}$} & & & \\
\hline & & & & & & & & \\
\hline \multicolumn{9}{|c|}{$\begin{array}{l}\text { Pathological tumor } \\
\text { classification (central) }\end{array}$} \\
\hline pT2a & 9 & 2 & 0 & 0 & 0 & $81.8 \%$ & $0.0 \%$ & $18.2 \%$ \\
\hline $\mathrm{pT} 2 \mathrm{~b}$ & 0 & 2 & 0 & 0 & 0 & $100.0 \%$ & $0.0 \%$ & $0.0 \%$ \\
\hline pT2c & 1 & 5 & 127 & 7 & 0 & $90.7 \%$ & $4.3 \%$ & $5.0 \%$ \\
\hline рT3a & 3 & 2 & 13 & 74 & 3 & $77.9 \%$ & $18.9 \%$ & $3.2 \%$ \\
\hline pT3b & 0 & 0 & 0 & 0 & 31 & $100.0 \%$ & $0.0 \%$ & $0.0 \%$ \\
\hline
\end{tabular}

This article is protected by copyright. All rights reserved. 
Table 2: Distribution of primary and secondary Gleason Pattern and Gleason Score after local vs. central pathological assessment

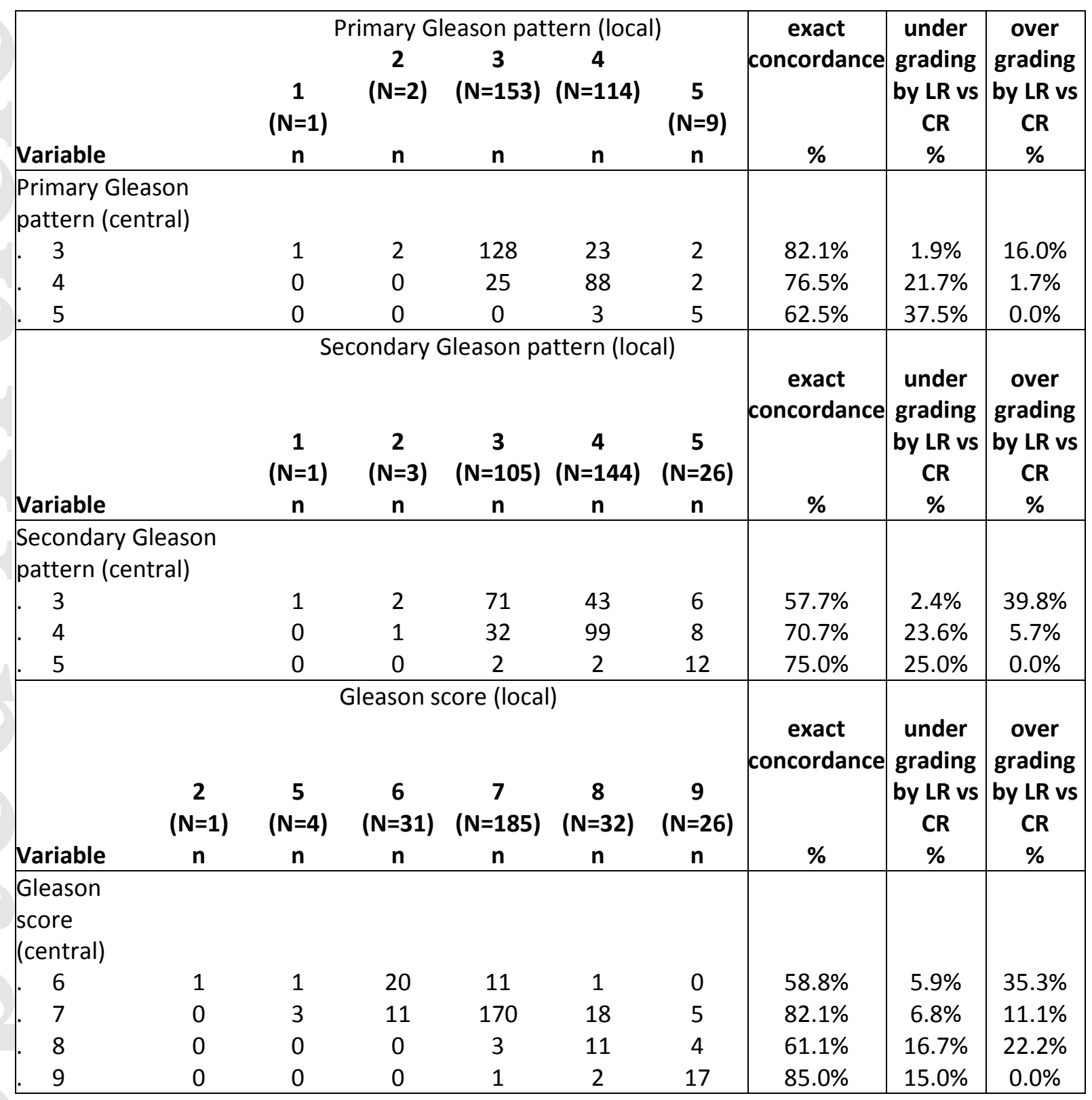

This article is protected by copyright. All rights reserved. 
Table 3: Continuous variables of the central pathology review

\begin{tabular}{|lccc|}
\hline \multicolumn{1}{|c}{ Variable } & \multicolumn{3}{c}{ Overall } \\
& (N=279) \\
& $\mathbf{n}$ & median & (min, max) \\
\hline Gleason score (central) & 279 & 7.0 & $(6.0,9.0)$ \\
Largest diameter of carcinoma (mm) & 279 & 16.0 & $(3.0,38.0)$ \\
Gleason score of largest cancer lesion & 279 & 7.0 & $(5.0,10.0)$ \\
Diameter of highest Gleason lesion (mm) & 279 & 15.0 & $(2.0,38.0)$ \\
Percentage of tumor tissue & 279 & 9.0 & $(0.5,66.0)$ \\
Size of positive resection margin $(\mathrm{mm})$ & 133 & 2.0 & $(0.3,90.0)$ \\
Gleason score within positive resection margin & 132 & 7.0 & $(6.0,10.0)$ \\
\hline
\end{tabular}

This article is protected by copyright. All rights reserved. 
Table 4: Variables from central pathology review by dichotomized PSA change

\begin{tabular}{|c|c|c|c|}
\hline & $\begin{array}{l}\text { PSA response or } \\
\text { stable PSA }\end{array}$ & $\begin{array}{l}\text { Rapid biochemical } \\
\text { progression }\end{array}$ & p-value \\
\hline Categorical variables & & & $\begin{array}{l}\text { Fisher's } \\
\text { exact test }\end{array}$ \\
\hline $\begin{array}{l}\text { Pathological tumor classification } \\
\text { (central) }\end{array}$ & & & 0.5 \\
\hline pT2a & 10 (90.9\%) & 1 (9.1\%) & \\
\hline pT2b & 2 (100.0\%) & 0 (0.0\%) & \\
\hline pT2c & $116(84.1 \%)$ & $22(15.9 \%)$ & \\
\hline рТ3а & $72(76.6 \%)$ & $22(23.4 \%)$ & \\
\hline . $\quad$ TT3b & 27 (87.1\%) & $4(12.9 \%)$ & \\
\hline Perineural invasion & & & 0.009 \\
\hline . No & $34(97.1 \%)$ & $1(2.9 \%)$ & \\
\hline . Yes & $193(80.1 \%)$ & $48(19.9 \%)$ & \\
\hline Seminal vesical infiltration & & & 0.6 \\
\hline . No & $199(81.6 \%)$ & $45(18.4 \%)$ & \\
\hline . Yes & $27(87.1 \%)$ & $4(12.9 \%)$ & \\
\hline Lymphovascular invasion & & & 0.3 \\
\hline No & $203(83.2 \%)$ & $41(16.8 \%)$ & \\
\hline . Yes & $24(75.0 \%)$ & $8(25.0 \%)$ & \\
\hline Extraprostatic growth & & & 0.3 \\
\hline . No & $128(84.8 \%)$ & $23(15.1 \%)$ & \\
\hline Yes & 99 (79.2\%) & $26(21.0 \%)$ & \\
\hline Resection margins & & & 0.03 \\
\hline . $\mathrm{RO}$ & 67 (80.7\%) & $16(19.3 \%)$ & \\
\hline . $\mathrm{R} 1$ & 69 (93.2\%) & $5(6.8 \%)$ & \\
\hline Continuous variables & & & $\begin{array}{c}\text { Wilcoxon } \\
\text { rank sum } \\
\text { test }\end{array}$ \\
\hline Gleason score (central) & $7.0(6.0-9.0)$ & $7.0(6.0-9.0)$ & 0.04 \\
\hline $\begin{array}{l}\text { Gleason score of largest cancer } \\
\text { lesion }\end{array}$ & $7.0(5.0-10.0)$ & $7.0(6.0-9.0)$ & 0.02 \\
\hline $\begin{array}{l}\text { Largest diameter of carcinoma } \\
(\mathrm{mm})\end{array}$ & $16.0(3.0-38.0)$ & $18.0(9.0-35.0)$ & 0.003 \\
\hline $\begin{array}{l}\text { Diameter of highest Gleason } \\
\text { lesion }(\mathrm{mm})\end{array}$ & $14.0(2.0-38.0)$ & $17.0(2.0-35.0)$ & 0.007 \\
\hline Percentage of tumor tissue & $9.0(0.5-66.0)$ & $13.0(1.0-51.0)$ & 0.02 \\
\hline $\begin{array}{l}\text { Size of positive resection margin } \\
(\mathrm{mm})\end{array}$ & $3.0(0.3-90.0)$ & $1.0(1.0-20.0)$ & 0.5 \\
\hline
\end{tabular}

This article is protected by copyright. All rights reserved. 
Table 5: Multivariable regression model for the association of variables of the central pathology review and other potentially prognostic variables with dichotomized PSA change

\begin{tabular}{|c|c|c|}
\hline Variable & $\begin{array}{l}\text { Odds Ratio (95\% } \\
\text { CI) }\end{array}$ & $\begin{array}{l}\text { p-value } \\
\text { (Wald } \\
\text { Chi-Square } \\
\text { test) }\end{array}$ \\
\hline \multicolumn{3}{|l|}{ Results of multiple logistic regression (full model) } \\
\hline Resection margins ( $\mathrm{R} 1$ vs R0) & $1.64(1.01-2.65)$ & 0.046 \\
\hline Largest diameter of carcinoma $(\mathrm{mm})^{*}$ & $0.32(0.15-0.69)$ & 0.004 \\
\hline Age at random assignment (years) & $1.91(1.18-3.09)$ & 0.008 \\
\hline $\mathrm{BMI}\left(\mathrm{kg} / \mathrm{m}^{2}\right)$ & $1.01(0.95-1.07)$ & 0.7 \\
\hline Lymphadenectomy performed (no [cNO] vs yes [pNO]) & $1.01(0.93-1.10)$ & 0.8 \\
\hline Prostatectomy technique (laparoscopic vs robotically assisted) & $0.97(0.32-2.94)$ & 1.0 \\
\hline Prostatectomy technique (other vs robotically assisted) & $2.30(0.65-8.07)$ & 0.2 \\
\hline Nerve-sparing technique (bilateral vs unilateral) & $1.39(0.53-3.67)$ & 0.5 \\
\hline Nerve-sparing technique (none vs unilateral) & $0.73(0.27-1.97)$ & 0.5 \\
\hline PSA at randomization $(\mathrm{ng} / \mathrm{mL})$ & $0.85(0.35-2.11)$ & 0.7 \\
\hline PSA doubling time from prostatectomy to randomization (months) & $0.88(0.25-3.08)$ & 0.8 \\
\hline \multicolumn{3}{|l|}{$\begin{array}{l}\text { Results of multiple logistic regression (after backward selection with } \\
\text { significance level 0.05) }\end{array}$} \\
\hline Gleason score & $1.55(1.00-2.42)$ & 0.05 \\
\hline Resection margins ( $\mathrm{R} 1$ vs R0) & $0.36(0.18-0.72)$ & 0.004 \\
\hline Largest diameter of carcinoma $(\mathrm{mm})^{*}$ & $2.04(1.30-3.20)$ & 0.002 \\
\hline
\end{tabular}

Abbreviations: *IQR-normalized for easier interpretation

This article is protected by copyright. All rights reserved. 